\title{
Saldino-Mainzer syndrome
}

INSERM

\section{Source}

INSERM. (1999). Orphanet: an online rare disease and orphan drug data base. SaldinoMainzer syndrome. ORPHA:140969

Saldino-Mainzer syndrome is characterised by the association of renal disease, retinal pigmentary dystrophy, cerebellar ataxia and skeletal dysplasia. 